\title{
HEREDITARY FRUCTOSE INTOLERANCE IN A GURKHA FAMILY
}

\author{
MAJ T GRAHAM, MB, BAO, MRCP, DCH, RAMC \\ British Military Hospital, Hong Kong*
}

\section{SUMMARY: Three siblings of a Gurkha family with Hereditary Fructose Intoler- ance (HFI) are described.}

The genetics and pathology of the disease, together with practical implications for the Army Medical Services, involved with Gurkhas, are discussed.

\section{Introduction}

Hereditary Fructose Intolerance (HFI) began to appear in the literature after Chambers and Pratt ${ }^{1}$ in 1956 described an adult with an idiosyncrasy to fructose. Froesch, Prader and colleagues ${ }^{2}$, the following year, described, for the first time the typical syndrome of HFI. Since then, over one hundred patients have been described from around the world indicating a wide distribution of this genetic defect, except Israel. The frequency is estimated as 1:30,000 and it probably has an autosomal recessive pattern of inheritance. It has been reported more commonly from Europe where the consumption of sucrose containing foods appears to be high. The syndrome has never been described among Nepalese children and for this reason, together with its rarity, difficulty in diagnosis and management among Gurkhas it was felt worthwhile recording this family.

\section{Case 1}

\section{Case reports}

The first child of the family, male, was born in Hong Kong. Delivery was normal and there were no neonatal problems. It was breast fed for the first nine months and thrived normally. Artificial feeding was then introduced. At the age of 10 months the infant was admitted to the British Military Hospital (BMH) as an emergency and died shortly after admission. Since this happened some time ago, no admission notes are available and therefore the cause of death is obscure.

\section{Case 2}

The second child of the family, female, was born in BMH Hong Kong. Again, delivery was normal and there were no neonatal problems. Like her brother she was breast fed for the first 10 months of life and then introduced to lactogen.

At one year old she was admitted to BMH Hong Kong with pyrexia and a bulging right tympanic membrane. Treatment consisted of myringotomy and antibiotics, and the condition settled within one week. During this admission, it was recorded that the liver was four fingers enlarged and the spleen by two fingers. She was readmitted approximately one and a half months later with a twelve

*Now Royal Air Force Hospital, Wegburg. 
hour history of vomiting. Examination revealed a dehydrated acidotic baby with hepatosplenomegaly as before. Initial investigations showed a blood glucose of $0.33 \mathrm{mmol} /$ litre. Electrolytes were normal. Liver function tests were disturbed; serum bilirubin was $23.8 \mathrm{mmol} /$ litre, alkaline phosphatase $202.7 \mathrm{IU}$, SGOT 350 units and LDH 253 units.

After resuscitation and stabilisation further investigations were performed. The glucose tolerance test was normal as also was the adrenaline test. Liver biopsy was reponted as low enzyme activity, fatty changes present but no infiltrations. This biopsy was interpreted in London. Fructose tolerance test was then carried out and the results obtained as shown in Table I. The prompt and dramatic fall in blood

Table I

Results of fructose tolerance test (Case 2)

\begin{tabular}{ccc}
\hline Time (minutes) & Blood glucose (mmol/litre) & $\begin{array}{c}\text { Inorganic phosphates } \\
\text { (mmol/litre) }\end{array}$ \\
\hline Fasting & 4.67 & 1.40 \\
15 & 3.9 & 0.96 \\
30 & 1.92 & 1.05 \\
45 & 1.26 & 1.05 \\
60 & 1.26 & 1.12 \\
75 & 1.65 & 0.86 \\
90 & 2.25 & 0.86 \\
\hline
\end{tabular}

glucose can be seen together with the more gradual decline of serum phosphate (Pi). Treatment was commenced with a fructose free diet and outpatient follow-up was arranged. Unfortunately, the child died in Nepal at the age of six years. The cause of death is not known.

\section{Case 3}

The third child, male, was born in Nepal in April 1976. Like the other two siblings he was breast fed initially but lactogen supplements were introduced at the age of 13 months. By this time, the family had returned to Hong Kong. There were no problems until a few days before admission to BMH on 2 July 1977. Then the mother had taken him to her own doctor complaining that he was generally unwell. He was diagnosed as an upper respiratory traict infection and given ampicillin and Phenergan elixir. Admission to hospital was arranged because of lack of improvement together with a 12 hour history of vomiting brown coloured fluid. On examination he was found to be a large floppy baby with marked air hunger. He remained remarkably quiet during the examination, lumbar puncture and venepuncture. The liver was $4 \mathrm{~cm}$ enlarged but the spleen was not palpable. Initial investigations showed a blood glucose of $0.6 \mathrm{mmol} / \mathrm{litre}$, normal electrolytes and normal cerebrospinal fluid.

Resuscitation was commenced with intravenous (IV) 50 per cent Dextrose and a 10 per cent IV infusion was left in situ until the child was capable of eating and drinking. Intravenous glucagon did not have any effect on the hypoglycaemia. It was noted that in spite of high blood glucose levels, clinical improvement was not complete until 10 hours after admission. When information of the family 
history was obtained from the general practitioner, a fructose tolerance test was performed three days after admission.

The results are shown in Table II. Before the commencement of the test a slow IV infusion of normal saline was erected. This proved life saving as the test had to be abandoned because of symptomatic hypoglycaemia and 50 per cent Dextrose had to be given via this route.

Table II

Results of fructose tolerance test (Case 3)

\begin{tabular}{ccc}
\hline Time (minutes) & Blood glucose (mmol/litre) & $\begin{array}{c}\text { Inorganic phosphate } \\
\text { (mmol/litre) }\end{array}$ \\
\hline Fasting & 2.6 & 1.80 \\
15 & 1.3 & 1.72 \\
30 & 0.8 & 1.65 \\
45 & 0.7 & 1.57 \\
\hline
\end{tabular}

Note: The test was abandoned at 45 minutes because of symptomatic hypoglycaemia and the child resuscitated.

The child was discharged from hospital after a fructose free diet had been carefully explained to the parents. Copies of food allowed and those to be avoided were also given to the family doctor and the Gurkha family hospital. In spite of this, and the fact that the father was a sergeant working in the Medical Centre, the patient required numerous admissions during the following year for the management of hypoglycaemia.

\section{Pathology}

The breakdown of fructose in the liver of a normal individual and its entry into both the gluconeogenic and glycogen pathways is well known. However it is interesting to note that an intravenous fructose load in the normal can raise the concentration of fructose-1-phosphate in the liver to 10-15 micromols within a few minutes after injection. The concentration of inorganic phosphate and adenosine triphosphate fall to about one third normal. The total amount of adenine nucleotides decrease and adenosine monophosphate is degraded to inosine monophosphate which accumulates but is then further metabolised to uric acid. This decrease of the adenine nucleotides disturbs protein synthesis in the liver. The clinical importance of this remains to be investigated.

Since fructose is not utilised as such by muscle, heart or brain but is converted largely to glucose in the liver there is not much point in using it therapeutically. Furthermore it does not correct the effect of hypoglycaemia since it does not cross the blood brain barrier. The defect in hereditary fructose intolerance appears to be a marked reduction in the activity of aldolase B in the liver, kidney and intestine.

Fructose is phosphorylated into fructos-1-phosphate by fructokinase. Because of the reduced activity of aldolase B, fructose-1-phosphate accumulates in the liver and both inorganic phosphate and ATP levels fall. Furthermore there is an inhibition to the action of fruotokinase with consequent high blood levels of fructose and fructosuria. The increased level of fructose-1-phosphate and the deficiency of inorganic phosphate inhibit glycogenlysis at the activation or action of 
phosphorylase A. A block in gluconeogenesis also contributes to the hypoglycaemia due to the inhibition of both glucose phosphate isomerase and the triosephosphate condensing activity of aldolase B by fructose-1-phosphate.

Morris and associates ${ }^{3}$ found extensive renal abnormalities following the administration or oral or intravenous fructose in subjects with HFI. The lack of response to glucagon in these patients is best explained by a decreased activity of liver phosphorylase $\mathrm{A}$ as a result of the fall in the concentration of inorganic phosphate and of the inhibition by fructose-1-phosphate which accumulates. Increased peripheral utilisation of glucose does not occur since no change or an actual fall in insulin levels, after fructose administration has been found by immunoassay. Invert sugar, sorbitol and laevulose have the same effects as fructose on patients with HFI and should be avoided.

\section{Discussion}

The clinical manifestations of hereditary fructose intolerance depend upon the age of the first exposure to fructose and the duration of such exposure. They are more severe in the infant and especially the first born. This is because they mimic other conditions such as pyloric stenosis, galactosaemia, hereditary tyrosinaemia, haemmorhagic disease of the newborn, hepatitis, congenital cirrhosis, cytomegalic inclusion disease or toxoplasmosis. The disease has been described in much older children and adults. It then presents mainly as gastro-intestinal discomfort and only a delayed hypoglycaemic response. Phillips $e t a^{4}$ reported proteinuria and striking electron microscopic liver changes two hours after ingestion of fifty grams of fructose in an adult male with HFI. Renal calculi and polyuria have also been described. Periodic or progressive weakness and paralysis have been reported.

The diagnosis in children, without a family history is difficult. Symptoms only appear after the introduction of fructose into the diet. Breast fed babies are symptom free which is not the case with galactosaemia. All our cases presented after the supplementation of replacement of breast milk with Laotogen (Nestles). This milk which is the cheapest and most popular in Hong Kong contains 12 per cent sucrose. This is broken down into glucose and fructose.

The classical presentation of HFI has been described as follows:-

"In the first few weeks of life, the infants may have anorexia, prolonged vomiting, failure to thrive and hypochromic anaemia. The vomitus may be projectile, blood stained, or just spitting up. Periodic attacks of hypoglycaemia with apnoeic spells, occasionally unconsciousness and convulsions have been reported". ${ }^{5}$

If fructose containing foods are continued, the disease progresses to more serious signs of liver failure including hypo-albuminaemia, abdominal distension with ascites, generalised oedema and deficiencies of hepatic coagulation factors. Haemmorhagic manifestations have been prominent in some infants who have had prolonged prothrombin times, plus reductions in factors 5, 7, 10 and fibrinogen as well as elevations in factor 8 . Some of these abnormalities have followed a fructose tolerance test. Other manifestations of the disease are elevated hepatic enzymes, elevated serum tyrosine and methionine, severe metabolic acidosis, 
albuminuria and amino-aciduria. The metabolic acidosis is due to a combination of renal acidosis and hyperlactic acidaemia.

The cases described in this paper were all initially breast fed hence the late onset of symptoms. The first baby died undiagnosed but on retrospective questioning the parents maintained that his symptoms were identical to those in Case 3. The experience of this sudden death was profitable both to the parents and medical staff when presented with the other two siblings. In Hong Kong there was a slow but gradual decline in breast feeding among Gurkha mothers and more reliance on artificial milks. Indeed, three deaths from severe gastro-enteritis occurred among bottle fed babies in the past two years.

It must be emphasised that provided fructose is excluded from the diet, these children lead a normal life. In Case 3 hepatomegaly disappeared and liver enzymes returned to normal. As the child grows older he develops a distaste for all sweet foods, and as the symptoms are less severe with advanoing age it is desirable to keep the young child under strict medical supervision as long as possible. This presents problems, since the average stay of a Gurkha family in Hong Kong is three years. Permission was obtained for our family to stay in the Colony pending progress reports from the Medical Services. There are a number of other families retained for a variety of medical problems and this imposes difficulties for the Gurkha administration.

A number of useful points arise from these cases. The finst is the importance of communication between medical centre and hospital. Because of the frequent moves of both general practitioners and hospital specialists there should be an index of problem families, either kept in the appropriate hospital department or the Gurkha family hospital or both. It is my opinion that such records would be more appropriately kept in the families hospital. This is mainly because the Gurkha nursing staff are more permanent and tend to know the Regimental families. They could then inform the duty doctor. However, this point is open to discussion. Secondly, there are very real difficulties in controlling the diet of a Gurkha child. A list of foods which were allowed was given to the parents. This was translated into Gurkhali with the help of QARANC Gurkha Sisters. A more detailed diet sheet, including foods to be avoided more appropriate to Gurkha needs, was also translated into Gurkhali and distributed to the Regimental Medical Officer, Gurkha family hospital and hospital kitchen.

In spite of these measures, Case 3 required numerous admissions to hospital for emergency treatment. It is possible that fructose containing foods were given to the child by neighbours or other children. It is difficult to persuade people not to give sweets. Another interesting problem which arose from this study is the type of medicines available in paediatric practice. Most are in liquid form with a sugar base. These are not suitable for patients and good liaison must exist between the pharmacy, general practitioner and hospital specialist if their use is to be avoided.

As previously stated, the inheritance of HFI is probably autosomal recessive and our family is no exception. Because of the close breeding among Gurkhas and the prolonged breast feeding which still exists it is interesting to postulate on the true incidence of this disease. In Hong Kong, the Army Medical Services have 
the families under their care for a very short time. Maybe some of the sudden unexplained deaths in Nepal are due to HFI.

\section{REFERENCES}

1. Chambers, R A and Pratt, Y T C (1956). Idiosyncrasy to fructose. Lancet 2, 340.

2. FRZESCH, $\mathrm{E} R$ et al (1957). Die hereditäre fructoseintoleranz, eine bisher niche bekannte kongenitale stoffwechselistörung. Schweizerische medizinische Wochenschrift 87, 1168.

3. MoRrIs, R C J (1969). Journal of Clinical Investigation 47, 1648.

4. Phillips, M J et al (1968). Subcellular pathology of hereditary fructose intolerance. American Journal of Medicine 44, 910.

5. DISORDERS OF OARBOHYDRATE METABOLISM IN INFANCY (1976). Vol III. Cornblach and Schwartz.

\section{ACADEMIC ACHIEVEMENTS}

MD

MSc

(Community Medicine)

MSc

(Prosthetic Dentistry)

\section{FFARCS}

MRCP(UK)

MRCPath
LT COL A J SPICER, MB, BS, MRCP, MRCS, DTM\&H, DCH, RAMC.

LT COL D H COOMBE, MB, BS, LRCP, MRCS, DTM\&H, RAMC.

MAJ J A GAMON, BDS, RADC.

MAJ S T INGLIS, MB, BS, MRCS, LRCP, RAMC.

CAPT K FREEMAN, MB, BS, MRCS, LRCP, LMSSA, RAMC.

MAJ P GRAVETT, MB, BS, MRCS, LRCP, RAMC. 